\title{
FIELD CONTROL OF CHLORPYRIFOS-RESISTANT MEALYBUGS (PSEUDOCOCCUS AFFINIS) IN A HAWKES BAY ORCHARD
}

\author{
J.T.S. WALKER', V. WHITE ${ }^{1}$ and J.G. CHARLES ${ }^{2}$ \\ HortResearch, 'Private Bag 1401, Havelock North. \\ and ${ }^{2}$ Private Bag 92 169, Auckland
}

\section{SUMMARY}

A field trial was conducted to evaluate chlorpyrifos resistance in mealybugs on a Hawkes Bay pear orchard. Four insecticides were evaluated, two organophosphates (OP), chlorpyrifos and prothiofos, and two insect growth regulators (kinoprene and buprofezin). Applications for each product were timed to coincide with standard control procedures (dormant, pre-flowering and November) and were followed by a standard insect control programme. Mealybug control was assessed at harvest. Neither of the recommended treatments (chlorpyrifos or prothiofos), or kinoprene, gave any significant level of mealybug control or suppression. A high level of mealybug control was achieved with buprofezin. Recommendations for mealybug control with chlorpyrifos and buprofezin are discussed.

Keywords: mealybug, Pseudococcus affinis, insecticides, resistance, control

\section{INTRODUCTION}

Control of the mealybug Pseudococcus affinis in Hawkes Bay orchards has become more difficult since the mid 1980's. At first these problems were restricted to old pear blocks but increasingly, poor mealybug control and the associated problem of sooty mould, has begun to occur in apples, particularly the cultivar "Royal Gala". Charles et al. (1993) found populations of the mealybug Pseudococcus affinis in Hawkes Bay orchards to be resistant to chlorpyrifos. Their work, using a laboratory bioassay and a discriminating dose to identify populations with suspected resistance, provided useful information on the variation in sensitivity of mealybug populations to chlorpyrifos. However, the impact of mealybug resistance to chlorpyrifos could only be confirmed through field trials. This study investigated field control of one of these mealybug populations with a high level of resistance to chlorpyrifos ( $37 \%$ survival, Charles et al. 1993). It also investigated options for insecticidal control of chlorpyrifosresistant mealybugs in Hawkes Bay orchards.

\section{METHODS}

The trial was conducted on a block of very old pear trees in a Hawkes Bay orchard with a history of mealybug control problems (Orchard 1, Charles et al. 1993) during the 1991-92 season. The block consisted of two cultivars, "William Bon Chretian" (WBC) and "Winter Nellis", with the latter dominant ( 25 of 32 trees). The trees were 6-7 m high, planted at $6 \times 6 \mathrm{~m}$ spacings and trained on a traditional "vase" system. There were seven insecticidal treatments that were specific for mealybug and an untreated control. Each treatment consisted of four single tree replicates which were arranged in a randomised complete block design. Four treatments (Table 1) were based on two insect growth regulator (IGR) insecticides kinoprene (Enstar) and buprofezin (Applaud 25W). Two currently recommended treatments, chlorpyrifos (Lorsban $40 \mathrm{EC}$ and 50WP) and prothiofos (Tokuthion 500EC), were compared while control in one treatment was based on oil alone.

All treatments were applied with $2 \%$ oil to dormant trees on August 30, 1991 using a high pressure hand gun. This was followed by pre-flowering applications of

Proc. 46th N.Z. Plant Protection Conf. 1993: 126-128 
kinoprene, buprofezin, prothiofos and chlorpyrifos to Treatments 1, 3, 4 and 6 respectively on September 6 . A further application of kinoprene and buprofezin was applied on November 19 to Treatments 1 and 4 while chlorpyrifos was applied to Treatments 5 and 6 . No other specific measures were taken for mealybug control. The grower applied a standard insect control programme (azinphos-methyl) to all treatments by airblast sprayer at 2-3 weekly intervals from early November until harvest.

Mealybug control was assessed on fruit twice, on January 31 and on March 20, 1992 , these dates corresponding to the harvest times for "WBC" and "Winter Nellis" pears respectively. January sampling consisted of 300 fruit/tree taken from each of the 32 trees. March sampling consisted of 200 fruit/tree taken only from the 25 "Winter Nellis" trees. All fruit were cut and inspected for the presence of mealybugs and/or sooty mould associated with mealybug feeding activity. January harvest data were analysed using ANOVA of angular transformed data of mealybug infested fruit and sooty mould contaminated fruit. March harvest data were also analysed using ANOVA angular transformations but as a completely random design because January data analysis found no significant $(\mathrm{P}>0.05)$ block effects.

\section{RESULTS AND DISCUSSION}

The incidence of mealybug infested fruit was high in control trees, increasing from almost $13 \%$ in late January to over $40 \%$ of fruit by mid-March (Table 1 ). This suggested that the grower's azinphos-methyl spray programme did not have a major impact on the development of the mealybug population in trees at the trial site.

In January there were significant differences between the experimental treatments in the incidence of mealybug and sooty mould damage. The three buprofezin treatments provided similar levels of mealybug control and were significantly different from the untreated control treatment. The single application of buprofezin was not significantly different to any of the other treatments. None of the other treatments were significantly different to the untreated. The incidence of sooty mould contaminated fruit was relatively low in late January.

TABLE: 1 The percentages of mealybug bug infested and sooty mould damaged fruit in January and March samples. Data shown are the untransformed percentages. Numbers with a letter in common are not significantly different at $\mathbf{P} \leq \mathbf{0 . 0 5}$.

\begin{tabular}{|c|c|c|c|c|c|c|}
\hline \multirow[t]{2}{*}{ Treatments } & \multirow[b]{2}{*}{$\begin{array}{l}\text { No. of } \\
\text { applns }\end{array}$} & \multirow[b]{2}{*}{$\begin{array}{c}\text { Rate } \\
\mathrm{g} \mathrm{ai} / 100 \\
\text { litres }\end{array}$} & \multicolumn{2}{|c|}{ January damage } & \multicolumn{2}{|c|}{ March damage } \\
\hline & & & $\begin{array}{l}\text { Mealy } \\
\text { bug }\end{array}$ & $\begin{array}{l}\text { Sooty } \\
\text { mould }\end{array}$ & $\begin{array}{l}\text { Mealy } \\
\text { bug }\end{array}$ & $\begin{array}{l}\text { Sooty } \\
\text { mould }\end{array}$ \\
\hline Kinoprene & 3 & 95 & $10.29 b c$ & $5.76 \mathrm{e}$ & $39.50 \mathrm{~cd}$ & $43.67 b$ \\
\hline Buprofezin & 1 & 12.5 & $3.38 \mathrm{ab}$ & $1.45 \mathrm{bcd}$ & $12.62 \mathrm{abc}$ & $18.33 b$ \\
\hline Buprofezin & 2 & 12.5 & $0.42 \mathrm{a}$ & $0.34 \mathrm{ab}$ & $5.25 \mathrm{ab}$ & $5.50 \mathrm{ab}$ \\
\hline Buprofezin & 3 & 12.5 & $0.67 \mathrm{a}$ & $0.08 \mathrm{a}$ & $0.50 \mathrm{a}$ & $0.00 \mathrm{a}$ \\
\hline $\begin{array}{c}\text { Prothiofos plus } \\
\text { chlorpyrifos }\end{array}$ & $\begin{array}{l}2+ \\
1\end{array}$ & $\begin{array}{c}50,30+ \\
38\end{array}$ & $6.42 \mathrm{bc}$ & $3.24 \mathrm{cde}$ & $35.57 \mathrm{~cd}$ & $38.67 \mathrm{~b}$ \\
\hline Chlorpyrifos & 3 & $40,40,38$ & $10.25 \mathrm{bc}$ & $4.88 \mathrm{cde}$ & $30.67 \mathrm{bcd}$ & $39.67 b$ \\
\hline Oil only & 1 & 2 litres & $9.42 b c$ & $1.50 \mathrm{abc}$ & $35.44 \mathrm{~cd}$ & $37.50 \mathrm{~b}$ \\
\hline Control & nil & nil & $12.95 \mathrm{c}$ & $4.46 \mathrm{de}$ & $41.42 d$ & $41.67 \mathrm{~b}$ \\
\hline
\end{tabular}

By March the incidence of mealybug had increased in all treatments between the assessments except where three applications of buprofezin had been applied. While none of the buprofezin treatments were significantly different, the incidence of mealybug infestation increased progressively with the two and one application treatments. None of the other treatments were significantly better than the untreated control. This suggested that neither chlorpyrifos, prothiofos or kinoprene gave any 
significant level of control when used against this resistant population of mealybugs. The incidence of sooty mould mirrored the mealybug infestation levels. Sooty mould incidence declined with increasing applications of buprofezin but only three applications gave significantly lower levels on the fruit at harvest.

\section{CONCLUSIONS}

This trial confirms that it is not grower management practices (eg. spray coverage, tree management) which are responsible for poor mealybug control in Hawkes Bay orchards. The trial found chlorpyrifos to be ineffectual for the control of mealybugs at this site, a confirmation of the results of laboratory bioassays (Charles et al. 1993). It also confirmed suspected mealybug resistance to prothiofos, the principal alternative insecticide for mealybug control. The laboratory bioassay on this population found $37 \%$ survival of mealybugs at the discriminating dose of chlorpyrifos. This level of survival equates with little or no suppression of this mealybug population at recommended field rates for chlorpyrifos and prothiofos. Better short term control of mealybugs may be achieved with either chlorpyrifos and prothiofos where laboratory bioassays have found mealybug populations with lower levels of survival (Charles et al. 1993). However, significant mealybug problems have already developed in some of these blocks under chlorpyrifos and prothiofos programmes.

Buprofezin was found to be highly effective for the control of this resistant population, while kinoprene gave no useful level of suppression. Under less severe mealybug pressure it is probable that either one or two pre-flowering applications of buprofezin, in conjunction with a standard OP programme (post-flowering), might provide season-long control of mealybugs. Charles et al. (1993) found that chlorpyrifos resistance in $P$. affinis quickly decreased in the absence of chlorpyrifos selection pressure. This suggests that substitution with buprofezin might be a useful chlorpyrifos resistance management strategy on properties where control has become difficult with this product. Before this strategy is adopted by growers consideration should be given to tree management practices which have probably influenced the development of OP resistance in mealybugs. This includes reducing the probability of poor spray coverage by; reducing the height of trees, developing open tree canopies, removing sucker growth and careful calibration of spray application equipment.

\section{ACKNOWLEDGEMENTS}

We wish to thank the New Zealand Apple and Pear Marketing Board for providing funding support for this project.

\section{REFERENCES}

Charles, J.G.; Walker, J.T.S. and White, V., 1993. Resistance to chlorpyrifos in the mealybugs Pseudococcus affinis and P. longispinus in Hawkes Bay and Waikato pipfruit orchards. Proc. 46th N.Z. Plant Protection Conf:: this volume. 